\title{
Blood lead level is associated with non- alcoholic fatty liver disease in the Yangtze River Delta region of China in the context of rapid urbanization
}

Hualing Zhai ${ }^{\dagger}$, Chi Chen ${ }^{\dagger}$, Ningjian Wang ${ }^{*}$, Yi Chen, Xiaomin Nie, Bing Han, Qin Li, Fangzhen Xia and Yingli Lu*

\begin{abstract}
Background: China has undergone rapid urbanization in the past three decades. We aimed to report blood lead level (B-Pb) in the most rapidly urbanized Yangtze River Delta Region of China, and explore the association B-Pb and non-alcoholic fatty liver disease (NAFLD).

Methods: Our data source was the SPECT-China study. We enrolled 2011 subjects from 6 villages in the Yangtze River Delta Region. Lead was measured by atomic absorption spectrometry. According to abdominal ultrasound, residents were divided into normal and NAFLD groups.

Results: In total, 824 (41.0\%) were diagnosed with NAFLD. Medians (interquartile range) of B-Pb were $5.29 \mu \mathrm{g} / \mathrm{dL}$ (3.

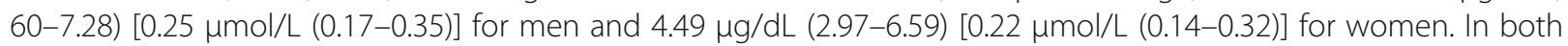
genders, the NAFLD group had significantly greater B-Pb than normal group (both $P<0.001$ ). The prevalence of NAFLD significantly increased with increasing B-Pb quartiles in men ( $P$ for trend $=0.032$ ) and women ( $P$ for trend $=0.001)$. Residents in Shanghai had significantly greater $\mathrm{B}-\mathrm{Pb}(P<0.001)$ and a higher prevalence of NAFLD $(P<0.001)$. Compared with women in the lowest quartile of BLL, OR of NAFLD in women in the highest quartile was $1.613(95 \% \mathrm{Cl} 1.082-2.405)$ ( $P$ for trend $=0.019)$ after multivariable adjustment. In men, this association showed marginal significance $(\mathrm{OR} 2.168,95 \% \mathrm{Cl}$ 0.989-4.750, $P$ for trend $=0.063)$.
\end{abstract}

Conclusion: $\mathrm{B}-\mathrm{Pb}$ in Chinese residents in the Yangtze River Delta Region were much higher than in developed countries. Elevated B-Pb was associated with an increased risk of NAFLD, especially in women.

Keywords: Lead, Non-alcoholic fatty liver disease, Urbanization, Chinese

\section{Background}

The prevalence of non-alcoholic fatty liver disease (NAFLD) is rising globally along with its associated conditions: obesity, dyslipidemia, insulin resistance and metabolic syndrome $[1,2]$. A study from China reported that up to $42 \%$ of adults are affected by NAFLD [3]. The rise in the prevalence of NAFLD parallels with increased exposure to endocrine disruptors or endocrine-disrupting chemicals [4].

\footnotetext{
*Correspondence: wnj486@126.com; luyingli2008@126.com

${ }^{\dagger}$ Equal contributors

Institute and Department of Endocrinology and Metabolism, Shanghai Ninth People's Hospital, Shanghai JiaoTong University School of Medicine, Shanghai 200011, China
}

(c) The Author(s). 2017 Open Access This article is distributed under the terms of the Creative Commons Attribution 4.0 International License (http://creativecommons.org/licenses/by/4.0/), which permits unrestricted use, distribution, and reproduction in any medium, provided you give appropriate credit to the original author(s) and the source, provide a link to the Creative Commons license, and indicate if changes were made. The Creative Commons Public Domain Dedication waiver (http://creativecommons.org/publicdomain/zero/1.0/) applies to the data made available in this article, unless otherwise stated.

Recent evidence has gradually shown that differential exposures to environmental toxicants may play a role in the pathogenesis of NAFLD. Data from the National Health and Nutrition Examination Survey III suggested that environmental cadmium exposure was associated with NAFLD in men [5]. Another study also reported that exposure to polychlorinated biphenyls in addition to heavy metals, such as lead and mercury was associated with suspected NAFLD [6].

Lead is a nonessential xenobiotic that is considered an endocrine disrupting chemical. For decades, leaded gasoline was the dominant source of human exposure to lead. Although the Chinese government banned the use of leaded gasoline in 2000, the burgeoning lead-acid 
battery industry [7], the emerging e-waste recycling activities [8] and metal smelting [9] have become other large anthropogenic sources of lead pollution. Lead can be airborne or deposited on objects and can enter the human body via the ingestion of contaminated food and water, the inhalation of dust, and dermal contact [10].

Regardless of the route of exposure, the absorbed lead is conjugated in the liver, which is considered the largest lead repository and the target organ for its toxic effects [11-13]. Experimental studies have shown that chronic lead exposure can cause an elevation in alanine aminotransferase (ALT), aspartate aminotransferase, and alkaline phosphatase $[14,15]$. Epidemiologic studies exploring the association between blood lead level (B-Pb) and NAFLD are scarce. Using data from NHANES 2003-2004, Cave et al. [6] reported that $\mathrm{B}-\mathrm{Pb}$ was positively associated with suspected NAFLD after adjustment for age, race, sex, body mass index, poverty income ratio, and insulin resistance. However, no study has explored the association between $\mathrm{B}-\mathrm{Pb}$ and NAFLD in Chinese adults so far.

Traditionally, Chinese society is divided into a ruralurban dual system based on economic and cultural disparities [16]. Compared to their rural counterparts, urban Chinese residents tend to have more educational and medical resources, better social welfare programs and higherpaying jobs [17]. Over the past three decades, the Chinese government has launched the largest-scale urbanization in human history. The Yangtze River Delta Region is located on the east coast of China, consisting of two provinces (Jiangsu, Zhejiang) and one municipality (Shanghai). During the past 30 years, this region has experienced a remarkable period of population growth and accelerated urbanization and is now the most rapidly urbanized region in China (China City Statistical Year Book, 2014). However, rapid urbanization may also cause serious environmental pollution and an increasing prevalence of noncommunicable diseases, posing challenges to sustainable development in this region $[18,19]$. Based on the investigation conducted by the Ministry of Land and Resources of China in 2014, approximately $19.4 \%$ of the agricultural soils have exceeded the national standards for lead, and among them the Yangtze River Delta Region is one of the most seriously polluted areas [20].

The 2014 Survey on Prevalence in East China for Metabolic Diseases and Risk Factors (SPECT-China, 2014) measured the $\mathrm{B}-\mathrm{Pb}$ in a Chinese population. Using these data, we aimed to explore the current $\mathrm{B}-\mathrm{Pb}$ in the Yangtze River Delta Region, and further investigate the association between $\mathrm{B}-\mathrm{Pb}$ and NAFLD.

\section{Methods}

\section{Study population}

The Yangtze River Delta region is the richest and most urbanized area in China. Taking in the belt of land abutting the Yangtze River, it covers $1.13 \%$ of the total land of China but supports $7.06 \%$ of the nation's population (96.05 million) [18]. Benefiting from rapid economic development and fast-going urbanization, this region accounted for $17.19 \%$ of the nation's Gross Domestic Product in 2013 [18]. The urbanization level of this region increased staggeringly from $20.55 \%$ in 1980 to $72.23 \%$ in 2013 , resulting in a growth rate of $1.41 \%$, which is 1.34 times the national average of $0.92 \%$ (China City Statistical Year Book, 2014). SPECT-China is a population-based cross-sectional survey on the prevalence of metabolic diseases and risk factors in East China from February to June 2014 (ChiCTR-ECS-14005052, www.chictr.org.cn) [21-23], in which six villages of the Yangtze River Delta Region were randomly chosen (Fig 1). Three villages were randomly chosen from the Fengcheng community, which is located in Southern Shanghai, $40 \mathrm{~km}$ away from the downtown. The other three villages were randomly chosen from the Xiaoyue community, which is located in eastern Shaoxing city (Zhejiang) adjacent to Hangzhou Bay, $45 \mathrm{~km}$ away from downtown. With rapid urbanization of the Yangtze River Delta region, residents living in these areas have experienced a rapid shift from peasant to citizen. Citizens $\geq 18$ years old who had lived in their current area for at least 6 months were selected and invited to participate in the study. Those with severe communication problems, acute illness or those who were unwilling to participate were excluded from the study The overall response rate was $90.8 \%$ [21]. A total of 3427 subjects were enrolled from 3 villages in Shanghai and 3 villages in the Zhejiang province, among whom 2557 participants had no history of excessive alcohol consumption (male $>20 \mathrm{~g} / \mathrm{d}$, female $>10 \mathrm{~g} / \mathrm{d}$ ) and viral hepatitis (selfreported). Exclusion criteria included the following: missing abdominal ultrasound (US) results $(n=59)$, missing values of ALT $(n=1)$ and B-Pb $(n=486)$. After exclusions, the study included a total number of 2011 subjects with a mean \pm SD age of $54 \pm 13$ years.

The study protocol was approved by the Ethics Committee of the Shanghai Ninth People's Hospital, Shanghai Jiaotong University School of Medicine. All procedures followed were in accordance with the ethical standards of the responsible committee on human experimentation (institutional and national) and with the Helsinki Declaration of 1975, as revised in 2008. All participants provided informed written consents before data collection.

Anthropometric and laboratory measurements At every study site, the same trained staff collected the information on socio-demographic characteristics, medical history, and lifestyle-related risk factors using a pretested questionnaire. Current smoking was defined as having smoked at least 100 cigarettes in one's lifetime 


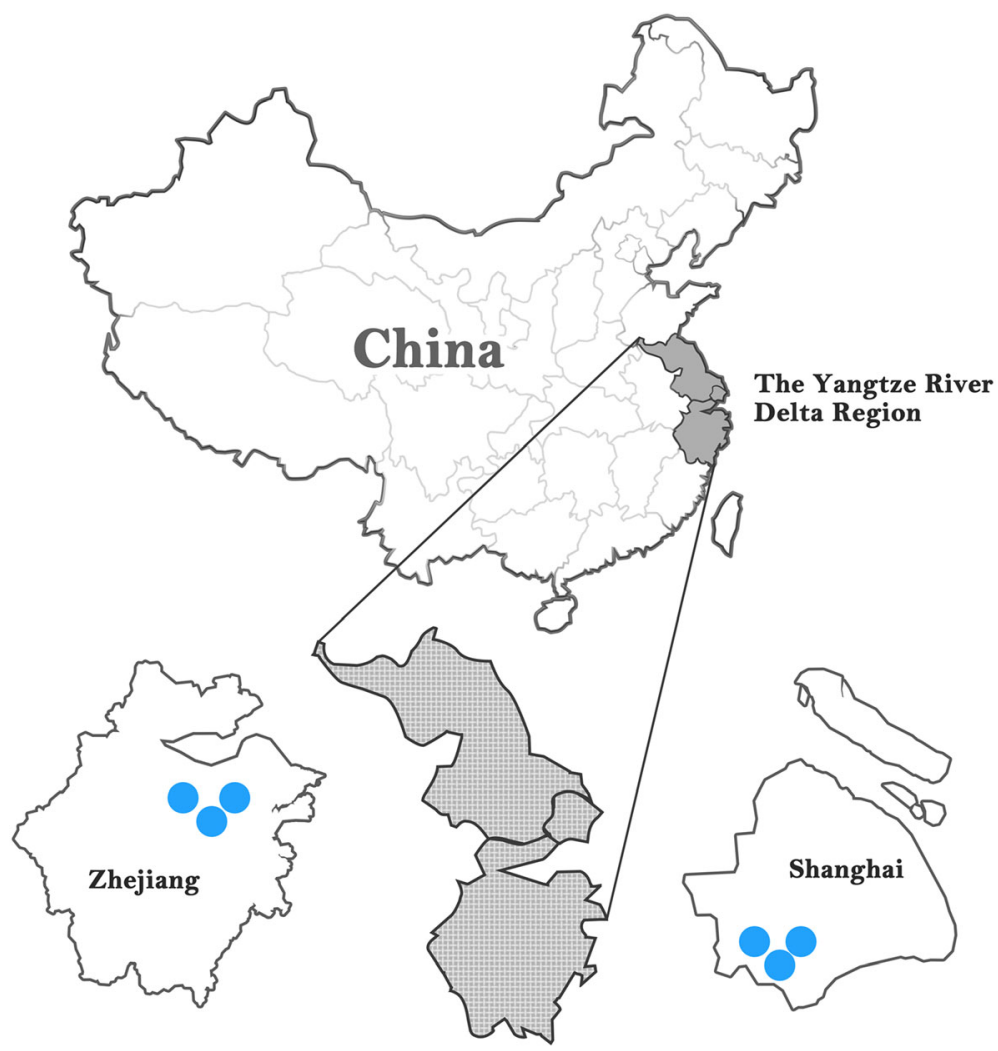

Fig. 1 Locations of survey sites in the Yangtze River Delta region of China

and currently smoking cigarettes [24]. Standing height and body weight were measured with light clothing and no shoes. BMI was calculated as the weight in kilograms divided by the height in meters squared. Waist circumference (WC) was measured on the mid-axillary line at the midpoint between the lower border of the rib cage and the upper margin of the iliac crest.

Venous blood samples were drawn after an overnight fast of at least $8 \mathrm{~h}$ from all subjects. The blood samples for the fasting plasma glucose (FPG) assessment were centrifuged at the site of collection within $1 \mathrm{~h}$ of collection. Other blood samples were shipped in dry ice within 2-4 h of collection to a central laboratory, which was certified by the College of American Pathologists. B-Pb was determined by atomic absorption spectrometry (BH2200, China). Standard curves were established with $r>0.9950$, and quality control materials were tested before samples were measured. Two quality control personnel participated in the process control. Outliers were detected by duplicate runs. The detection limits for blood lead were $0.1 \mu \mathrm{g} / \mathrm{L}$. None of the samples exhibited values below the detection limits of blood lead. The inter-assay coefficient of variation for lead was $10 \%$. Glycated hemoglobin (HbA1C) was assessed by highperformance liquid chromatography (MQ-2000PT, China). FPG, total cholesterol, triglycerides, high density lipoprotein, low-density lipoprotein and ALT were detected using standard laboratory methods. The laboratory methods were consistent throughout the study period. All blood samples were tested using an auto-analyzer at the central laboratory (BECKMAN COULTER AU 680 Germany).

Definition of variables An abdominal ultrasonic (US) examination was performed on all participants using a B-mode ultrasound device (MINDRAY M7, China) by two trained US doctors who were blinded to the clinical and laboratory data. According to the criteria described previously $[25,26]$, the ultrasonographic findings were categorized into two patterns: normal, homogenous liver parenchyma with medium-level echogenicity and a regular hepatic surface; and fatty liver, discrete coarse and heterogeneous parenchymal echogenicity and dotted, irregular or nodular hepatic liver surface. In accordance with the American Diabetes Association 2014 criteria, diabetes was defined as a previous diagnosis by healthcare professionals, FPG $\geq 7.0 \mathrm{mmol} / \mathrm{L}$, or $\mathrm{HbA} 1 \mathrm{c} \geq 6.5 \%$.

Statistical analysis All data analyses were performed with IBM SPSS Statistics, Version 22 (IBM Corporation, Armonk, NY, USA). Two-sided $P$ values $<0.05$ were considered significant. General characteristics were summarized as the median and interquartile range for continuous variables or as the number and proportion for categorical 
variables. To test for differences in variables among different groups, the Kruskal-Wallis test was used for continuous variables with a skewed distribution, and the Pearson chisquare test was used for categorical variables.

To determine the risk of NAFLD for each quartile of B$\mathrm{Pb}$, the binary logistic regression analysis was applied with the lowest $\mathrm{B}-\mathrm{Pb}$ quartile as reference. The data were expressed as odds ratio (OR) and 95\% confidence intervals (CIs). Model 1 was unadjusted. Model 2 included terms for age, geography (Shanghai/Zhejiang), educational level, current smoking, current drinking and ALT. Model 3 was further adjusted for diabetes, WC, BMI, low-density lipoprotein, high-density lipoprotein, triglycerides, total cholesterol and cadmium. WC was adjusted, because it may be better than body mass index as an alternative measure of body fat deposition for predicting cardio-metabolic risks $[27,28]$. Moreover, among Chinese adults, people are more likely to have generally low BMI but visceral adiposity [29].

\section{Results}

General demographic and laboratory characteristics of the study population categorized by the presence/absence of NAFLD are presented in Table 1. Overall, the prevalence of NAFLD was $41.0 \%$ in this study population $(40.8 \%$ in men and $41.0 \%$ in women). Medians (IQR) of $\mathrm{B}-\mathrm{Pb}$ were $5.29 \mu \mathrm{g} / \mathrm{dL}(3.60-7.28)[0.25 \mu \mathrm{mol} / \mathrm{L}(0.17-0.35)]$ for men and $4.49 \mu \mathrm{g} / \mathrm{dL}(2.97-6.59)[0.22 \mu \mathrm{mol} / \mathrm{L}(0.14-0.32)]$ for women. Compared to subjects without NAFLD, both men and women with NAFLD had significantly higher $\mathrm{B}-\mathrm{Pb}$ levels (men: $5.65(4.00-7.76)$ vs $5.12(3.30-6.90) \mu \mathrm{g} / \mathrm{dL}[0.27$ $(0.19-0.37)$ vs $0.25(0.16-0.33) \mu \mathrm{mol} / \mathrm{L}], P=0.006$; women: $4.80(3.20-6.94)$ vs $4.24(2.80-6.24) \mu \mathrm{g} / \mathrm{dL}[0.23(0.15-0.33)$ vs $0.20(0.13-0.30) \mu \mathrm{mol} / \mathrm{L}], P<0.001)$. Moreover, subjects of both genders with NAFLD had a greater ALT and WC, a worse lipid profile, and a higher prevalence of diabetes.

The characteristics of the study population according to quartiles of $\mathrm{B}-\mathrm{Pb}$ are summarized in Table 2. Compared with those in the lowest quartile, subjects of both genders in the highest quartile were older and more likely to have lower educational levels $(P<0.05)$. Additionally, with increasing $\mathrm{B}-\mathrm{Pb}$ quartiles, women had a significantly greater $\mathrm{WC}$ and BMI and a worse lipid profile $(P$ for trend $<0.05$ ). However, such trend was not observed across the $\mathrm{B}-\mathrm{Pb}$ quartiles in men ( $P$ for trend $>0.05)$.

Additional file 1: Tables S1 and S2 summarize the results of $\mathrm{B}-\mathrm{Pb}$ and metabolic factors by geography. Compared with those living in Zhejiang, residents in Shanghai had significantly higher B-Pb (5.54 (4.03-7.78) vs $3.55(2.50-5.30) \mu \mathrm{g} / \mathrm{dL}[0.27(0.19-0.37)$ vs 0.17 $(0.12-0.25) \mu \mathrm{mol} / \mathrm{L}], P<0.001)$, and also a higher prevalence of NAFLD (45.7\% vs $35.1 \%, P<0.001)$.

The prevalence of NALFD in participants according to B$\mathrm{Pb}$ quartiles are presented in Fig. 2. The prevalence of NAFLD gradually and markedly increased with increasing $\mathrm{B}-\mathrm{Pb}$ quartiles in both men $(P$ for trend $=0.032)$ and women $(P$ for trend $=0.001)$.

Table 1 Demographic and general characteristics of the study participants

\begin{tabular}{|c|c|c|c|c|c|c|}
\hline & \multicolumn{2}{|l|}{ Men } & \multirow[b]{2}{*}{$P$} & \multicolumn{2}{|l|}{ Women } & \multirow[b]{2}{*}{$P$} \\
\hline & Non-NAFLD & NAFLD & & Non-NAFLD & NFALD & \\
\hline $\mathrm{N}$ & 311 & 214 & & 876 & 610 & \\
\hline Age, yr & $56(44-64)$ & $57(44-66)$ & 0.723 & $51(41-61)$ & $59(51-64)$ & $<0.001$ \\
\hline Blood lead level, $\mu \mathrm{g} / \mathrm{dL}$ & $5.12(3.30-6.90)$ & $5.65(4.00-7.76)$ & 0.006 & $4.24(2.80-6.24)$ & $4.80(3.20-6.94)$ & $<0.001$ \\
\hline Blood cadmium level, $\mu \mathrm{g} / \mathrm{dL}$ & $0.15(0.05-0.32)$ & $0.21(0.08-0.36)$ & 0.017 & $0.14(0.05-0.31)$ & $0.16(0.06-0.31)$ & 0.295 \\
\hline $\mathrm{ALT}, \mathrm{U} / \mathrm{L}$ & $19.0(15.0-26.0)$ & $24.0(18.0-34.0)$ & $<0.001$ & $15.0(12.0-20.0)$ & $18.0(15.0-25.0)$ & $<0.001$ \\
\hline Educational level, \% & & & 0.380 & & & 0.001 \\
\hline$<$ High School & 76.0 & 77.9 & & 83.9 & 90.5 & \\
\hline High school & 15.4 & 16.8 & & 10.7 & 7.5 & \\
\hline >High School & 8.6 & 5.3 & & 5.4 & 2.0 & \\
\hline Waist circumference, $\mathrm{cm}$ & $76.5(72.0-83.0)$ & $86.0(82.0-92.0)$ & $<0.001$ & $72.0(68.0-78.0)$ & $83.0(77.0-89.0)$ & $<0.001$ \\
\hline Body mass index, $\mathrm{kg} / \mathrm{m}^{2}$ & $22.5(20.8-24.5)$ & $26.1(23.8-28.0)$ & $<0.001$ & $22.4(20.4-24.4)$ & $26.0(24.2-28.4)$ & $<0.001$ \\
\hline LDL-cholesterol, mmol/L & $2.67(2.26-3.09)$ & $2.92(2.46-3.38)$ & $<0.001$ & $2.63(2.24-3.09)$ & $2.97(2.54-3.43)$ & $<0.001$ \\
\hline HDL-cholesterol, mmol/L & $1.39(1.18-1.58)$ & $1.22(1.08-1.40)$ & $<0.001$ & $1.51(1.32-1.71)$ & $1.39(1.23-1.58)$ & $<0.001$ \\
\hline Triglycerides, mmol/L & $1.10(0.86-1.49)$ & $1.66(1.19-2.35)$ & $<0.001$ & $1.06(0.81-1.46)$ & $1.48(1.08-2.14)$ & $<0.001$ \\
\hline Total-cholesterol, mmol/L & $4.84(4.25-5.41)$ & $5.09(4.56-5.68)$ & 0.001 & $4.87(4.33-5.48)$ & $5.27(4.58-5.93)$ & $<0.001$ \\
\hline Diabetes, \% & 9.7 & 15.0 & 0.002 & 5.4 & 19.7 & 0.001 \\
\hline Current smoker, \% & 47.1 & 49.0 & 0.681 & 1.8 & 2.3 & 0.524 \\
\hline
\end{tabular}

Data were summarized as median with interquartile range for continuous variables or as number with proportion for categorical variables NAFLD non-alcoholic fatty liver disease, ALT alanine aminotransferase, $L D L$ low-density lipoprotein, HDL high-density lipoprotein 
Table 2 General characteristics of the study population by blood lead quartiles

\begin{tabular}{|c|c|c|c|c|c|}
\hline & Quartile 1 & Quartile 2 & Quartile 3 & Quartile 4 & $P$ for trend \\
\hline \multicolumn{6}{|l|}{ Men } \\
\hline $\mathrm{N}$ & 133 & 130 & 131 & 131 & \\
\hline Blood lead level, $\mu \mathrm{g} / \mathrm{dL}$ & $\leq 3.60$ & $3.61-5.29$ & $5.30-7.28$ & $\geq 7.29$ & \\
\hline Age, yr & $52(39-61)$ & $53(42-64)$ & $59(48-66)$ & $60(51-69)$ & $<0.001$ \\
\hline Blood cadmium level, $\mu \mathrm{g} / \mathrm{dL}$ & $0.07(0.04-0.23)$ & $0.16(0.07-0.29))$ & $0.19(0.08-0.33)$ & $0.30(0.12-0.45)$ & $<0.001$ \\
\hline Educational level, \% & & & & & $<0.001$ \\
\hline$<$ High School & 69.3 & 69.6 & 84.5 & 82.5 & \\
\hline High school & 17.5 & 21.4 & 12.2 & 13.3 & \\
\hline$>$ High School & 13.2 & 9.0 & 3.3 & 4.2 & \\
\hline$A L T, U / L$ & $21.0(17.0-33.0)$ & $20.0(16.0-27.0)$ & $21.0(16.0-28.0)$ & $20.0(15.0-28.0)$ & 0.062 \\
\hline Waist circumference, cm & $80.0(74.0-86.0)$ & $80.0(73.0-86.0)$ & $80.0(75.0-87.0)$ & $84.0(76.0-90.0)$ & 0.029 \\
\hline Body mass index, $\mathrm{kg} / \mathrm{m}^{2}$ & $24.5(21.6-26.3)$ & $23.6(21.1-26.0)$ & $23.7(21.7-26.0)$ & $24.1(22.0-27.3)$ & 0.157 \\
\hline LDL-cholesterol, mmol/L & $2.81(2.30-3.15)$ & $2.66(2.31-3.10)$ & $2.74(2.33-3.25)$ & $2.90(2.34-3.29)$ & 0.206 \\
\hline HDL-cholesterol, mmol/L & $1.34(1.17-1.54)$ & $1.34(1.09-1.53)$ & $1.28(1.10-1.49)$ & $1.32(1.14-1.52)$ & 0.340 \\
\hline Triglycerides, mmol/L & $1.30(0.90-1.85)$ & $1.28(0.96-1.74)$ & $1.33(0.93-1.99)$ & $1.28(0.97-1.90)$ & 0.817 \\
\hline Total-cholesterol, mmol/L & $4.92(4.37-5.56)$ & $4.84(4.31-5.43)$ & $4.93(4.26-5.47)$ & $4.95(4.38-5.60)$ & 0.694 \\
\hline Diabetes, \% & 12.0 & 7.7 & 12.3 & 15.3 & 0.017 \\
\hline Current smoker, \% & 46.5 & 54.5 & 52.8 & 39.0 & 0.076 \\
\hline \multicolumn{6}{|l|}{ Women } \\
\hline $\mathrm{N}$ & 372 & 371 & 372 & 371 & \\
\hline Blood lead level, $\mu \mathrm{g} / \mathrm{dL}$ & $\leq 2.97$ & $2.98-4.49$ & $4.50-6.59$ & $\geq 6.60$ & \\
\hline Age, yr & $52(41-60)$ & $53(43-62)$ & $54(45-63)$ & $59(50-66)$ & $<0.001$ \\
\hline Blood cadmium level, $\mu \mathrm{g} / \mathrm{dL}$ & $0.06(0.03-0.13)$ & $0.13(0.06-0.27)$ & $0.18(0.07-0.34)$ & $0.27(0.14-0.44)$ & $<0.001$ \\
\hline Educational level, \% & & & & & 0.001 \\
\hline$<$ High School & 84.1 & 82.2 & 89.1 & 90.9 & \\
\hline High school & 10.8 & 12.2 & 7.3 & 7.3 & \\
\hline$>$ High School & 5.1 & 5.6 & 3.6 & 1.8 & \\
\hline$A L T, U / L$ & $17.0(13.0-22.0)$ & $17.0(13.0-23.0)$ & $16.0(13.0-22.0)$ & $16.0(13.0-20.0)$ & 0.930 \\
\hline Waist circumference, cm & $75.0(70.0-82.0)$ & $76.0(70.0-82.0)$ & $76.0(70.0-84.3)$ & $79.0(72.0-85.0)$ & $<0.001$ \\
\hline Body mass index, $\mathrm{kg} / \mathrm{m}^{2}$ & $23.2(21.0-25.6)$ & $23.7(21.2-25.8)$ & $24.0(21.7-26.4)$ & $24.8(22.5-27.9)$ & $<0.001$ \\
\hline LDL-cholesterol, mmol/L & $2.61(2.24-3.18)$ & $2.68(2.28-3.16)$ & $2.80(2.35-3.31)$ & $2.94(2.56-3.40)$ & $<0.001$ \\
\hline HDL-cholesterol, mmol/L & $1.47(1.28-1.63)$ & $1.47(1.27-1.66)$ & $1.45(1.29-1.67)$ & $1.47(1.29-1.68)$ & 0.118 \\
\hline Triglycerides, mmol/L & $1.18(0.83-1.58)$ & $1.21(0.88-1.69)$ & $1.21(0.92-1.71)$ & $1.27(0.95-1.82)$ & 0.03 \\
\hline Total-cholesterol, mmol/L & $4.91(4.33-5.66)$ & $4.88(4.36-5.55)$ & $5.04(4.47-5.64)$ & $5.18(4.55-5.78)$ & 0.004 \\
\hline Diabetes, \% & 8.3 & 11.1 & 11.0 & 14.6 & 0.20 \\
\hline Current smoker, \% & 3.6 & 0.8 & 1.7 & 1.7 & 0.147 \\
\hline
\end{tabular}

Data were summarized as median with interquartile range for continuous variables or as number with proportion for categorical variables $A L T$ alanine aminotransferase, $L D L$ low-density lipoprotein, $H D L$ high-density lipoprotein

Table 3 demonstrates the results of binary logistic regression analyses measuring the association of $\mathrm{B}-\mathrm{Pb}$ with the risk for NAFLD. In the unadjusted model, compared to those in the lowest B-Pb quartile, the ORs of NAFLD in the highest quartile were 1.644 (95\% CI 1.003, 2.695) for men and 1.818 (95\% CI 1.353, 2.443) for women (Table 3, Model 1). Adjusting for socioeconomic variables and ALT did not weaken the association between B-Pb and NAFLD in either gender (Table 3, Model 2). Further adjustment for diabetes, WC, BMI, lipid profile and cadmium weakened this association such that it was only marginally significant in men [OR 2.168 (95\% CI 0.989-4.750), $P$ for trend $=0.063$ ); however, in women this association remained statistically significant [OR 1.613 (95\% CI 1.082, 2.405), $P$ for trend $=0.019]$. 


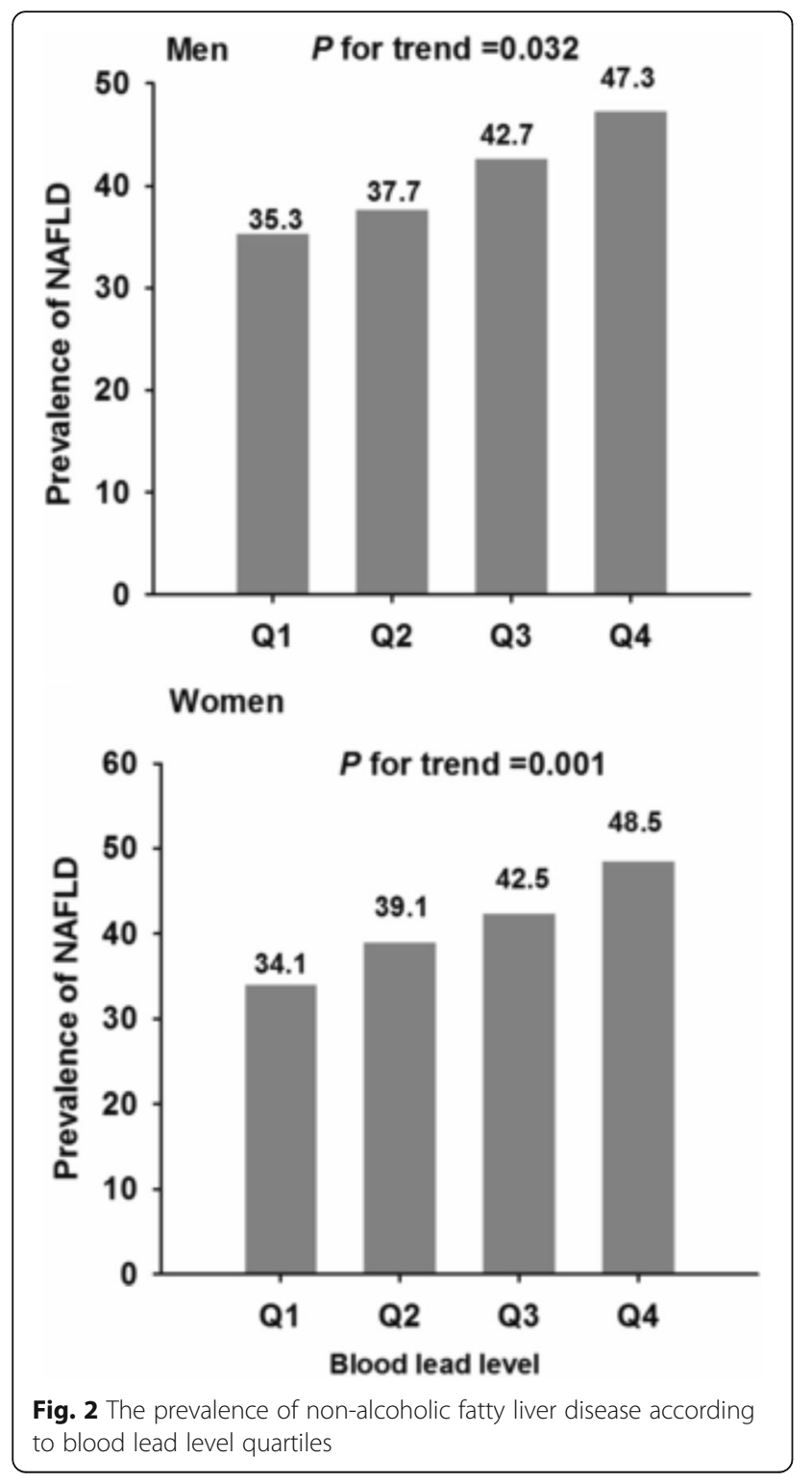

\section{Discussion}

To the best of our knowledge, this study reported $\mathrm{B}-\mathrm{Pb}$ in the largest sample of the general Chinese population living in the rapidly urbanized Yangtze River Delta Region. This study is also the first to explore the association between $\mathrm{B}-\mathrm{Pb}$ and NAFLD in Chinese adults. We found that $\mathrm{B}-\mathrm{Pb}$ was positively associated with NAFLD. This association was independent of liver function (ALT) and conventional NAFLD risk factors including lifestyle, WC, BMI, lipid profile, diabetes and cadmium.

China has been experiencing a period of accelerated urbanization since the 1990s. The Yangtze River Delta, the study area of the present paper, boasts a faster growth rate of urbanization than the national average level (China City Statistical Year book, 2014). Rapid urbanization results in changes in the lifestyles of residents [30]. Growing numbers of people have become reliant on automobiles and can afford computers, displacing vigorous physical activity with a sedentary lifestyle. Meanwhile, the consumption of low-value high-calorie options such as fast food has increased. A sedentary lifestyle and increased intake of calories are known risk factors for obesity, NAFLD and other metabolic diseases [31].

Urbanization not only encourages lifestyle changes but also causes changes in the urban environment, including air pollution and noise induced by construction and transportation, and soil and water pollution from waste disposal [32]. Based on the investigation conducted by the Ministry of Land and Resources of China in 2014, approximately $19.4 \%$ of the agricultural soils have exceeded the national standards for lead, and among them the Yangtze River Delta Region is one of the most seriously polluted areas [20]. Emerging evidence has shown that in addition to conventional risk factors, various environmental factors termed endocrine-disrupting chemicals can have an additive or synergistic effect on metabolic disorders [33].

Scarce epidemiologic studies have explored the association between lead exposure and NAFLD. In 2010, Cave et al. [6] reported that $\mathrm{B}-\mathrm{Pb}($ median $=1.60 \mu \mathrm{g} / \mathrm{dL})$ were positively associated with suspected NAFLD in 4582 participants based on data from the NHANES 2003-2004 [OR 1.6 (95\% CI 1.1, 2.3)]. To date, this study is the only epidemiologic investigation detecting an association between the $\mathrm{B}-\mathrm{Pb}$ and NAFLD. However, it is notable that in the NHANES study, NAFLD was defined by an elevation in ALT that was not attributable to viral hepatitis, hemochromatosis, or alcoholism. Considering that the ALT level may be normal in NAFLD and that there are many causes of increased ALT other than NAFLD, this definition has limitations. In contrast, we used ultrasound to screen for fatty liver and categorized the degree of fat accumulation into normal and fatty liver groups, which has a sensitivity of $94 \%$ and a specificity of $84 \%$ for detecting liver steatosis [34].. Additionally, compared with Cave et al.'s analysis, this study controlled for age, sex, BMI and current smoking, but also made additional adjustments for ALT, waist circumference, diabetes and lipid profile. Thus, the results from this analysis of $\mathrm{B}-\mathrm{Pb}$ and NAFLD may be more precise. Finally, the study by Cave et al. did not perform sex-specific analyses, though sex was adjusted.

The mechanism underlying the association between $\mathrm{B}-\mathrm{Pb}$ and NAFLD is not yet fully understood. First, oxidative stress may be involved. Lead exposure causes alterations in lipid peroxidation, overproduction of reactive oxygen species, and reduction in the activity of antioxidant enzymes, such as superoxide dismutase, catalase, and glutathione peroxidase in hepatocytes [14, 35-37]. Recent studies have shown that oxidative stress is related to the pathogenic mechanism of NAFLD [38]. Thus, it is reasonable to deduce that lead exposure may induce NAFLD partly through 
Table 3 Association of blood lead level with non-alcohol fatty liver disease

\begin{tabular}{|c|c|c|c|c|c|}
\hline \multirow[b]{2}{*}{ Variables } & \multicolumn{4}{|c|}{ Blood lead level quartiles } & \multirow[b]{2}{*}{$P$ for trend } \\
\hline & Q1 & Q2 & Q3 & Q4 & \\
\hline \multicolumn{6}{|l|}{ Men } \\
\hline Blood lead level, $\mu \mathrm{g} / \mathrm{dL}$ & $\leq 3.60$ & $3.61-5.29$ & $5.30-7.28$ & $\geq 7.29$ & \\
\hline \multicolumn{6}{|l|}{ NAFLD } \\
\hline Model 1 & Ref. & 1.107 (0.670-1.829) & $1.366(0.832-2.244)$ & $1.644(1.003-2.695)^{*}$ & 0.033 \\
\hline Model 2 & Ref. & $1.261(0.695-2.287)$ & $1.394(0.770-2.523)$ & $1.858(1.007-3.429)^{*}$ & 0.048 \\
\hline Model 3 & Ref. & $1.695(0.841-3.419)$ & $1.837(0.875-3.858)$ & $2.168(0.989-4.750)$ & 0.063 \\
\hline \multicolumn{6}{|l|}{ Women } \\
\hline Blood lead level, $\mu \mathrm{g} / \mathrm{dL}$ & $\leq 2.97$ & $2.98-4.49$ & $4.50-6.59$ & $\geq 6.60$ & \\
\hline \multicolumn{6}{|l|}{ NAFLD } \\
\hline Model 1 & Ref. & $1.238(0.918-1.669)$ & $1.424(1.058-1.917)^{*}$ & $1.818(1.353-2.443)^{* * *}$ & $<0.001$ \\
\hline Model 2 & Ref. & $1.276(0.915-1.779)$ & $1.585(1.140-2.204)^{* *}$ & $1.686(1.211-2.348)^{* *}$ & 0.001 \\
\hline Model 3 & Ref. & $1.384(0.956-2.005)$ & $1.495(1.024-2.181) *$ & $1.613(1.082-2.405)^{*}$ & 0.019 \\
\hline
\end{tabular}

Data were odds ratio $\left(95 \%\right.$ confidence interval). ${ }^{*} P<0.05 ;{ }^{* *} P<0.01 ;{ }^{* * *} P<0.001$

Model 1 was unadjusted

Model 2 was adjusted for age, geography (Shanghai/Zhejiang), educational level, current smoking, current drinking and alanine transaminase

Model 3 was additionally adjusted for diabetes, waist circumference, body mass index, low-density lipoprotein, high-density lipoprotein, triglycerides, total cholesterol and blood cadmium level

oxidative stress. In addition, lead stimulates intercellular signaling between hepatocytes and Kupffer cells, which contributes to lead-induced hepatotoxicity [39].

Accumulating evidence has shown that there is no safe threshold for $\mathrm{B}-\mathrm{Pb}$ [40]. Although the B-Pb has gradually dropped in the past decades [41], the median $\mathrm{B}-\mathrm{Pb}$ $(4.71 \mu \mathrm{g} / \mathrm{dL}[0.23 \mu \mathrm{mol} / \mathrm{L}])$ in Chinese residents in the rapidly urbanized Yangtze River Delta Region was still much higher than that in Americans $(0.84 \mu \mathrm{g} / \mathrm{dL}[0.04 \mu \mathrm{mol} / \mathrm{L}])$ based on the newest data from NHANES 2013-2014. [42]. Considering the fact that China's urbanization rate continues to move forward, our study may have important implications from a public health perspective. It is now time to pay attention to urbanization quality rather than to continue large-scale "destroy and build." Large numbers of people are experiencing remarkable lifestyle and environmental changes during the transition of urbanization. They should be encouraged to adopt healthy lifestyles, and more importantly, to participate in environmental monitoring and management.

Our study has some strengths. First, we have provided the newest data regarding the $\mathrm{B}-\mathrm{Pb}$ in a large population that has experienced rapid urbanization over the past three decades. This study is also the first to explore the association between $\mathrm{B}-\mathrm{Pb}$ and NAFLD in Chinese adults. Second, our study was a community-dwelling populationbased design, with a wide spectrum of information on confounders, so our results are more representative in comparison to a clinic-based population. However, our study also has some limitations. First, in light of the crosssectional nature of this study, we cannot infer any causeeffect relationships between $\mathrm{B}-\mathrm{Pb}$ and NAFLD. The $\mathrm{B}-\mathrm{Pb}$ concentration may be affected by liver function. However, we have already adjusted ALT in the logistic regression models. Even we reanalyzed the model within normal ALT level, the association between B-Pb and NAFLD remained robust. Prospective studies are needed to confirm our findings. Second, the use of liver ultrasound to diagnose NAFLD is operator-dependent. However, our US examinations were performed by the same two operators by consensus to minimize the deviation. Liver biopsy, the current gold standard for diagnosing NAFLD, was not possible in such a large epidemiological study.

\section{Conclusions}

We have demonstrated that an elevated $\mathrm{B}-\mathrm{Pb}$ was associated with an increased prevalence of NAFLD in a Chinese population undergoing rapid urbanization. Future prospective studies are warranted to confirm our findings.

\section{Additional file}

Additional file 1: Supplementary Tables. Table S1 Demographic and general characteristics of the study participants. Table S2 General characteristics of the study population by blood lead quartiles. (DOC $101 \mathrm{~kb}$ )

\section{Abbreviations}

ALT: Alanine aminotransferase; BMI: Body mass index; B-Pb: Blood lead level; Cl: Confidence interval; LDL-C: Low-density lipoprotein cholesterol;

NAFLD: Non-alcoholic fatty liver disease; NHANES: National Health and Nutrition Examination Survey; OR: Odds ratio; WC: Waist circumference

\section{Acknowledgements}

The authors are grateful to Weiping Tu, Bin Li and Ling Hu for helping organize this investigation. The authors also thank Olson Karen J (RN at the Mayo Clinic) for language editing. 


\section{Funding}

This study was supported by National Natural Science Foundation of China (81,270,885, 81,070,677, 81,300,653 and 81,600,609); Clinical Potential Subject Construction of Shanghai Jiaotong University School of Medicine (2014);

Science and Technology Commission of Shanghai Municipality

(14495810700); The Fourth Round of Three-year Public Health Action Plan of Shanghai (15GWZK0202).

\section{Availability of data and materials}

The datasets collected and/or analyzed during the current study are available from the corresponding author on reasonable request.

\section{Authors' contributions}

Y.L. had full access to all the data in the study and takes responsibility for the integrity of the data and the accuracy of the data analysis. Y.L. and N.W. were responsible for study concept and design. H.Z., C.C., N.W., Y.C., X.N., B.H., Q.L., and F.X. conducted the research; H.Z. analyzed the data; H.Z. and C.C. wrote the manuscript. All authors read and approved the final manuscript. Y.L. and N.W. are guarantors.

\section{Ethics approval and consent to participate}

Ethical approval was obtained from the Ethics Committee of the Shanghai Ninth People's Hospital, Shanghai Jiao Tong University School of Medicine. All participants provided written informed consent at enrollment.

\section{Consent for publication}

N/A

\section{Competing interests}

The authors declare that they have no competing interests.

\section{Publisher's Note}

Springer Nature remains neutral with regard to jurisdictional claims in published maps and institutional affiliations.

\section{Received: 28 March 2017 Accepted: 27 August 2017}

\section{Published online: 31 August 2017}

\section{References}

1. Masarone M, Federico A, Abenavoli L, Loguercio C, Persico M. Non alcoholic fatty liver: epidemiology and natural history. Rev Recent Clin Trials. 2014;9(3):126-33.

2. Vernon G, Baranova A, Younossi ZM. Systematic review: the epidemiology and natural history of non-alcoholic fatty liver disease and non-alcoholic steatohepatitis in adults. Aliment Pharmacol Ther. 2011:34(3):274-85.

3. Fung J, Lee CK, Chan M, Seto WK, Lai CL, Yuen MF. High prevalence of nonalcoholic fatty liver disease in the Chinese - results from the Hong Kong liver health census. Liver Int. 2015;35(2):542-9.

4. Polyzos SA, Kountouras J, Deretzi G, Zavos C, Mantzoros CS. The emerging role of endocrine disruptors in pathogenesis of insulin resistance: a concept implicating nonalcoholic fatty liver disease. Curr Mol Med. 2012;12(1):68-82.

5. Hyder O, Chung M, Cosgrove D, Herman JM, Li Z, Firoozmand A, Gurakar A, Koteish A, Pawlik TM. Cadmium exposure and liver disease among US adults. J Gastrointest Surg. 2013;17(7):1265-73.

6. Cave M, Appana S, Patel M, Falkner KC, McClain CJ, Brock G. Polychlorinated biphenyls, lead, and mercury are associated with liver disease in American adults: NHANES 2003-2004. Environ Health Perspect. 2010;118(12):1735-42.

7. van der Kuijp TJ, Huang L, Cherry CR. Health hazards of China's lead-acid battery industry: a review of its market drivers, production processes, and health impacts. Environ Health. 2013:12:61.

8. Huo X, Peng L, Xu X, Zheng L, Qiu B, Qi Z, Zhang B, Han D, Piao Z. Elevated blood lead levels of children in Guiyu, an electronic waste recycling town in China. Environ Health Perspect. 2007;115(7):1113-7.

9. Wu Y, Gu JM, Huang Y, Duan YY, Huang RX, Hu JA: Dose-response relationship between cumulative occupational lead exposure and the associated health damages: a 20-year cohort study of a smelter in China. Int J Environ Res Public Health. 2016;13(3). doi:10.3390/ijerph13030328.

10. Qu CS, Ma ZW, Yang J, Liu Y, Bi J, Huang L. Human exposure pathways of heavy metals in a lead-zinc mining area, Jiangsu Province, China. PLoS One. 2012;7(11):e46793.
11. Jarrar BM, Mahmoud ZN. Histochemical demonstration of changes in the activity of hepatic phosphatases induced by experimental lead poisoning in male white rats (Rattus Norvegicus). Toxicol Ind Health. 2000;16(1):7-15.

12. Patra RC, Swarup D, Dwivedi SK. Antioxidant effects of alpha tocopherol, ascorbic acid and L-methionine on lead induced oxidative stress to the liver, kidney and brain in rats. Toxicology. 2001;162(2):81-8.

13. Mudipalli A. Lead hepatotoxicity \& potential health effects. Indian J Med Res. 2007;126(6):518-27.

14. Berrahal AA, Lasram M, El Elj N, Kerkeni A, Gharbi N, El-Fazaa S. Effect of age-dependent exposure to lead on hepatotoxicity and nephrotoxicity in male rats. Environ Toxicol. 2011;26(1):68-78.

15. Alya A, Ines DB, Montassar L, Najoua G, Saloua el F. Oxidative stress, biochemical alterations, and hyperlipidemia in female rats induced by lead chronic toxicity during puberty and post puberty periods. Iran J Basic Med Sci. 2015:18(10):1034-43.

16. Li X, Stanton B, Fang X, Lin D. Social stigma and mental health among rural to-urban migrants in China: a conceptual framework and future research needs. World Health Popul. 2006;8(3):14-31.

17. Zheng J, An R. Satisfaction with local exercise facility: a rural-urban comparison in China. Rural Remote Health. 2015;15(1):2990.

18. Zhao $Y$, Wang S, Zhou C. Understanding the relation between urbanization and the eco-environment in China's Yangtze River Delta using an improved EKC model and coupling analysis. Sci Total Environ. 2016:571:862-75.

19. Li X, Wang C, Zhang G, Xiao L, Dixon J. Urbanisation and human health in China: spatial features and a systemic perspective. Environ Sci Pollut Res Int. 2012;19(5):1375-84.

20. Chen H, Yuan X, Li T, Hu S, Ji J, Wang C. Characteristics of heavy metal transfer and their influencing factors in different soil-crop systems of the industrialization region, China. Ecotoxicol Environ Saf. 2016;126:193-201.

21. Wang N, Wang X, Han B, Li Q, Chen Y, Zhu C, Chen Y, Xia F, Cang Z, Zhu $C$, et al. Is exposure to famine in childhood and economic development in adulthood associated with diabetes? J Clin Endocrino Metab. 2015;100(12):4514-23.

22. Jiang B, Li B, Wang Y, Han B, Wang N, Li Q, Yang W, Huang G, Wang J, Chen $Y$, et al. The nine-year changes of the incidence and characteristics of metabolic syndrome in China: longitudinal comparisons of the two crosssectional surveys in a newly formed urban community. Cardiovasc Diabetol. 2016;15:84.

23. Wang N, Wang X, Li Q, Han B, Chen Y, Zhu C, Chen Y, Lin D, Wang B, Jensen MD, et al. The famine exposure in early life and metabolic syndrome in adulthood. Clin Nutr. 2017;36(1):253-9.

24. Xu Y, Wang $L$, He J, Bi Y, Li M, Wang T, Wang L, Jiang $Y$, Dai M, Lu J, et al. Prevalence and control of diabetes in Chinese adults. JAMA. 2013; 310(9):948-59.

25. Hamaguchi M, Kojima T, Takeda N, Nagata C, Takeda J, Sarui H, Kawahito Y, Yoshida N, Suetsugu A, Kato T, et al. Nonalcoholic fatty liver disease is a novel predictor of cardiovascular disease. World J Gastroenterol. 2007;13(10):1579-84.

26. Saadeh S, Younossi ZM, Remer EM, Gramlich T, Ong JP, Hurley M, Mullen KD, Cooper JN, Sheridan MJ. The utility of radiological imaging in nonalcoholic fatty liver disease. Gastroenterol. 2002;123(3):745-50.

27. Zeng Q, He Y, Dong S, Zhao X, Chen Z, Song Z, Chang G, Yang F, Wang Y. Optimal cut-off values of BMl, waist circumference and waist: height ratio for defining obesity in Chinese adults. Br J Nutr. 2014; 112(10):1735-44.

28. Li R, Shi L, Jia J, Li Y, Yang Q, Ruan Y, Chen R, Kan H. Differentiating the associations of waist circumference and body mass index with cardiovascular disease risk in a Chinese population. Asia Pac J Public Health. 2015;27(2):Np457-67.

29. Zhang X, Shu XO, Li H, Yang G, Xiang YB, Cai Q, Ji BT, Gao YT, Zheng W. Visceral adiposity and risk of coronary heart disease in relatively lean Chinese adults. Int J Cardiol. 2013;168(3):2141-5.

30. Zhu YG, loannidis JP, Li H, Jones KC, Martin FL. Understanding and harnessing the health effects of rapid urbanization in China. Environ Sci Technol. 2011:45(12):5099-104.

31. Ramachandran A, Chamukuttan S, Shetty SA, Arun N, Susairaj P. Obesity in Asia-is it different from rest of the world. Diabetes Metab Res Rev. 2012; 28(Suppl 2):47-51

32. Li X, Song J, Lin T, Dixon J, Zhang G, Ye H. Urbanization and health in China, thinking at the national, local and individual levels. Environ Health. 2016;15(Suppl 1):32. 
33. Gore AC, Chappell VA, Fenton SE, Flaws JA, Nadal A, Prins GS, Toppari J, Zoeller RT. EDC-2: the Endocrine Society's second scientific statement on endocrine-disrupting chemicals. Endocr Rev. 2015;36(6):E1-e150.

34. Jimba S, Nakagami T, Takahashi M, Wakamatsu T, Hirota Y, Iwamoto Y, Wasada T. Prevalence of non-alcoholic fatty liver disease and its association with impaired glucose metabolism in Japanese adults. Diabet Med. 2005; 22(9):1141-5.

35. Kalender S, Apaydin FG, Bas H, Kalender Y. Protective effects of sodium selenite on lead nitrate-induced hepatotoxicity in diabetic and non-diabetic rats. Environ Toxicol Pharmacol. 2015;40(2):568-74.

36. Liu CM, Zheng GH, Ming QL, Sun JM, Cheng C. Protective effect of quercetin on lead-induced oxidative stress and endoplasmic reticulum stress in rat liver via the IRE1/JNK and PI3K/Akt pathway. Free Radic Res. 2013;47(3):192-201.

37. Omobowale TO, Oyagbemi AA, Akinrinde AS, Saba AB, Daramola OT, Ogunpolu BS, Olopade JO. Failure of recovery from lead induced hepatoxicity and disruption of erythrocyte antioxidant defence system in Wistar rats. Environ Toxicol Pharmacol. 2014;37(3):1202-11.

38. Martin-Dominguez V, Gonzalez-Casas R, Mendoza-Jimenez-Ridruejo J, Garcia-Buey L, Moreno-Otero R. Pathogenesis, diagnosis and treatment of non-alcoholic fatty liver disease. Rev Esp Enferm Dig. 2013;105(7):409-20.

39. Milosevic N, Maier P. Lead stimulates intercellular signalling between hepatocytes and Kupffer cells. Eur J Pharmacol. 2000;401(3):317-28.

40. Krishnan E, Lingala B, Bhalla V. Low-level lead exposure and the prevalence of gout: an observational study. Ann Intern Med. 2012;157(4):233-41.

41. Li MM, Cao J, Xu J, Cai SZ, Shen XM, Yan CH. The national trend of blood lead levels among Chinese children aged 0-18 years old, 1990-2012. Environ Int. 2014;71:109-17.

42. Tsoi MF, Cheung CL, Cheung TT, Cheung BM. Continual decrease in blood lead level in Americans: United States National Health Nutrition and examination survey 1999-2014. Am J Med. 2016;129(11):1213-8.

\section{Submit your next manuscript to BioMed Central and we will help you at every step:}

- We accept pre-submission inquiries

- Our selector tool helps you to find the most relevant journal

- We provide round the clock customer support

- Convenient online submission

- Thorough peer review

- Inclusion in PubMed and all major indexing services

- Maximum visibility for your research

Submit your manuscript at www.biomedcentral.com/submit

C) Biomed Central 